\title{
Phenotypic and genotypic diversity of wine yeasts used for acidic musts
}

\author{
Alina Kunicka-Styczyńska $\cdot$ Katarzyna Rajkowska
}

Received: 19 October 2011 / Accepted: 20 December 2011/Published online: 3 January 2012

(C) The Author(s) 2011. This article is published with open access at Springerlink.com

\begin{abstract}
The aim of this study was to examine the physiological and genetic stability of the industrial wine yeasts Saccharomyces cerevisiae and Saccharomyces bayanus var. uvarum under acidic stress during fermentation. The yeasts were sub-cultured in aerobic or fermentative conditions in media with or without L-malic acid. Changes in the biochemical profiles, karyotypes, and mitochondrial DNA profiles were assessed after minimum 50 generations. All yeast segregates showed a tendency to increase the range of compounds used as sole carbon sources. The wild strains and their segregates were aneuploidal or diploidal. One of the four strains of S. cerevisiae did not reveal any changes in the electrophoretic profiles of chromosomal and mitochondrial DNA, irrespective of culture conditions. The extent of genomic changes in the other yeasts was strain-dependent. In the karyotypes of the segregates, the loss of up to 2 and the appearance up to 3 bands was noted. The changes in their mtDNA patterns were much broader, reaching 5 missing and 10 additional bands. The only exception was $S$. bayanus var. uvarum Y.00779, characterized by significantly greater genome plasticity only under fermentative stress. Changes in karyotypes and mtDNA profiles prove that fermentative stress is the main driving force of the adaptive evolution of the yeasts. L-malic acid does not influence the extent of genomic changes and the resistance of wine yeasts exhibiting increased demalication activity to acidic stress is rather related to their ability to decompose this acid. The phenotypic changes in segregates, which were
\end{abstract}

A. Kunicka-Styczyńska $(\bowtie) \cdot$ K. Rajkowska Institute of Fermentation Technology and Microbiology, Technical University of Lodz, Wólczańska 171/173, 90-924 Lodz, Poland

e-mail: alina.kunicka@p.lodz.pl found even in yeasts that did not reveal deviations in their DNA profiles, show that phenotypic characterization may be misleading in wine yeast identification. Because of yeast gross genomic diversity, karyotyping even though it does not seem to be a good discriminative tool, can be useful in determining the stability of wine yeasts. Restriction analysis of mitochondrial DNA appears to be a more sensitive method allowing for an early detection of genotypic changes in yeasts. Thus, if both of these methods are applied, it is possible to conduct the quick routine assessment of wine yeast stability in pure culture collections depositing industrial strains.

Keywords Wine yeasts - Stability - Karyotyping . mtDNA restriction analysis $\cdot$ Malic acid

\section{Introduction}

The majority of industrial strains of wine yeasts are classified as Saccharomyces cerevisiae however Saccharomyces bayanus are also used. They are closely related, and both belong to the Saccharomyces sensu stricto complex. Due to the development of molecular methods in yeast characterization, some species within this group have been reclassified (Kurtzman 2003; for a review see Rainieri et al. 2003). Also there is a debate about the species $S$. bayanus, which includes strains with very different physiological and genetic features. Despite the ongoing discussion concerning yeast classification and nomenclature (for a review see Sipiczki 2008), there is still widespread parallel use of the taxon names $S$. bayanus, $S$. uvarum, and S. bayanus var. uvarum. The names of industrial strains remain unchanged, mostly for the convenience of the users and nomenclature of strains deposited in collections and applied as starters in 
wineries are usually not verified. Moreover, in light of the latest research, many wine yeasts are interspecific hybrids between yeasts of the Saccharomyces sensu stricto complex (Bradbury et al. 2006; Gonzalez et al. 2006, 2007; Le Jeune et al. 2007; Lopandic et al. 2007; Lopes et al. 2010). At the same time, wine yeasts are known for their genome plasticity, which has been explained by the necessity to adapt to the changeable conditions of the environment during fermentation (Querol et al. 2003; Sipiczki 2011). Due to the large capacity of wine yeasts for genome reorganization, they are regarded as undergoing constant adaptive evolution. The model of fast adaptive genome evolution (FAGE), suggested for wine yeasts, indicates the possibility of inducing genotypic changes both during vegetative growth and at the sexual stage (Sipiczki 2011). From the technological point of view, it is important to determine the stability of commercially used wine yeasts and their sensitivity to environmental stresses occurring during fermentation. The main fermentative stresses include osmotic, hyperosmotic, ethanol, oxidative and ionic stresses as well as low $\mathrm{pH}$, temperature shifts, nutrient limitation, and starvation (Cardona et al. 2007; Querol et al. 2003). Acidic stress adversely affects wine yeasts (Fleet and Heard 1993) and results in changes in the sensory properties of wines (Pretorius and Bauer 2002; Redzepovic et al. 2003). Acidic musts are one of the main problems in winery of cold regions countries, including Poland. Moreover, Polish wineries mostly rely on fruit musts rich in organic acids, so yeasts should be best suited for acidic environments. Biological deacidification with yeasts consuming organic acids leads to wines with the right balance between sugar, acid and aroma components (Volschenk et al. 2003). Tartaric and malic acids may constitute up to $90 \%$ of total organic acid content in must (Torija et al. 2003), but only L-malic acid is metabolized by yeasts during vinification, so L-malic acid decomposing yeasts are of the great value. Malate decomposition varies greatly and may reach $48 \%$, depending on the strain (Pretorius and Bauer 2002; Redzepovic et al. 2003). We have previously selected and characterized industrial wine yeasts $S$. cerevisiae and $S$. bayanus, with a demalication activity reaching 68\% (Rajkowska and Kunicka 2005), but their stability under acidic stress has not been examined. The objective of this paper was to investigate the physiological and genetic stability of selected $S$. cerevisiae and $S$. bayanus var. uvarum strains in the presence of malic acid. The yeasts were cultivated in standard media under aerobic and semi-anaerobic conditions, simultaneously being subjected to acidic stress. We assessed changes in the biochemical profiles of these industrial wine yeasts, their karyotypes and mitochondrial DNA (mtDNA) profiles after approximately 50-180 generations, depending on the strain and culture conditions. It is assumed that changes occurring in the population for up to 20 generations result from physiological response to environmental conditions, while changes in later generations reflect evolutionary processes (Fox 1998). Furthermore, it is also possible to assess the influence of environmental stresses on yeast phenotypes and genomes. Therefore, the study presented in this paper gives a fair picture of changes in yeast populations leading to their adaptive evolution. To our knowledge, this report is the first one concerning phenotypic and genotypic stability of yeasts with extended demalication activity.

\section{Materials and methods}

\section{Microorganisms}

The following wine yeasts were used: four strains $S$. cerevisiae (Syrena, W-13, Y.00911, Y.00925) and two strains S. bayanus var. uvarum (Cz-2 and Y.00779). S. cerevisiae Syrena and W-13 are industrial strains commonly used in Poland and deposited in the Collection of Pure Cultures of the Institute of Fermentation Technology and Microbiology, Technical University of Lodz, ŁOCK 105. S. cerevisiae Y.00911, Y.00925 and S. bayanus var. uvarum Y.00779 are originated from National Collection of Agricultural and Industrial Microorganisms University of Horticulture and Food Science in Budapest Hungary. Strain $\mathrm{Cz}-2$ was isolated from Italian dried wine yeast designated as S. bayanus and purchased from F.LLI MARESCALCHI S.p.A. (Casale Monferrato, Italy). Reference S. cerevisiae haploids Cm MATa and Gm MAT $\alpha$ originated from the Collection of the Institute of Agricultural Sciences in Zamosc, Poland. The microorganisms were activated through double passaging in YGP liquid medium (yeast extract $10 \mathrm{~g} \mathrm{l}^{-1}$, glucose $20 \mathrm{~g} \mathrm{l}^{-1}$, peptone $10 \mathrm{~g} \mathrm{l}^{-1}$ ) at $28^{\circ} \mathrm{C}$ for $48 \mathrm{~h}$.

To check homogeneity of industrial strains, yeasts from YGP liquid medium were restreaked on YGP agar plates (yeast extract $10 \mathrm{~g} \mathrm{l}^{-1}$, glucose $20 \mathrm{~g} \mathrm{l}^{-1}$, peptone $10 \mathrm{~g} \mathrm{l}^{-1}$, agar $20 \mathrm{~g} \mathrm{l}^{-1}$ ) and incubated at $28^{\circ} \mathrm{C}$ for $48 \mathrm{~h}$. Subsequently, 20 representative colonies were picked randomly from the plates, subjected to macro-morphological and micro-morphological analysis and no differences in morphological features were observed.

\section{Yeast segregates}

Yeasts were sub-cultured 20 times in aerobic or semianaerobic conditions in both YGP and YG (yeast extract $4 \mathrm{~g} \mathrm{l}^{-1}$, glucose $100 \mathrm{~g} \mathrm{l}^{-1}$, L-malic acid $7 \mathrm{~g} \mathrm{l}^{-1}, \mathrm{KH}_{2} \mathrm{PO}_{4}$ $5 \mathrm{~g} \mathrm{l}^{-1}, \mathrm{MgSO}_{4} 0.4 \mathrm{~g} \mathrm{l}^{-1}, \mathrm{pH}$ 3.0) media. Aerobic cultures were conducted in $50 \mathrm{ml}$ liquid YGP or YG medium at $28^{\circ} \mathrm{C}$ for $48 \mathrm{~h}$ in $500 \mathrm{ml}$ flat-bottomed flasks and constantly 
shaken $(200 \mathrm{rpm})$. Semi-anaerobically, yeasts were grown in $110 \mathrm{ml}$ YGP or YG medium in conical $250 \mathrm{ml}$ flasks for 7 days at $25^{\circ} \mathrm{C}$. The media were inoculated by $1 \%$ yeast cell suspensions in saline solution $\left(\mathrm{NaCl} 8.5 \mathrm{~g} \mathrm{l}^{-1}\right)$ standardized to a density of $10^{8}$ c.f.u. $1^{-1}$. Generation times were estimated for exponential growth phase according to Mesa et al. (1999). Numbers of generations were calculated independently for lag, exponential and stationary growth of yeasts and summarized.

After completing the last passage, yeast cells were centrifuged, resuspended in YGP medium and frozen at $-80^{\circ} \mathrm{C}$ with glycerol added to $50 \%$. Streaks from the evolved frozen samples on YGP were re-streaked on agar plates and incubated at $28^{\circ} \mathrm{C}$ for $48 \mathrm{~h}$. Subsequently, 10 representative colonies were picked randomly from the plates, subjected to macro-morphological and micro-morphological analysis. Because no differences in morphological features were observed, for each experiment four colonies of segregates were restreaked on YGP agar slants and independently tested.

Nomenclature used for yeast segregates is presented in Table 1.

\section{Biochemical profiles}

The biochemical ability of the yeasts and their segregates to assimilate 19 substrates (glucose, glycerol, 2-keto-Dgluconate, L-arabinose, D-xylose, adonitol, xylitol, galactose, inositol, sorbitol, $\alpha$-methyl-D-glucoside, $N$-acetyl-Dglucosamine, cellobiose, lactose, maltose, sucrose, trehalose, melezitose, raffinose) as sole carbon sources was checked with API 20C AUX tests (bioMerieux, Warsaw, Poland) according to the producer's guidelines. Glycerol, ethanol and nitrate assimilation as well as the fermentation of carbohydrates (glucose, galactose, maltose, lactose, sucrose, melibiose, raffinose, trehalose) were tested according to the procedure given by Barnett et al. (2000).

Table 1 Nomenclature used for segregates of yeasts

\begin{tabular}{|c|c|c|c|c|}
\hline & \multicolumn{2}{|c|}{ Aerobic segregates } & \multicolumn{2}{|c|}{ Semi-anaerobic segregates } \\
\hline & YGP & $\begin{array}{l}\text { YG + L-malic } \\
\text { acid }\end{array}$ & YGP & $\begin{array}{l}\text { YG + L-malic } \\
\text { acid }\end{array}$ \\
\hline \multicolumn{5}{|c|}{ S. cerevisiae } \\
\hline Syrena & C1-A & C1-B & $\mathrm{C} 1-\mathrm{C}$ & C1-D \\
\hline $\mathrm{W}-13$ & $\mathrm{C} 2-\mathrm{A}$ & $\mathrm{C} 2-\mathrm{B}$ & $\mathrm{C} 2-\mathrm{C}$ & C2-D \\
\hline Y.00911 & C3-A & C3-B & $\mathrm{C} 3-\mathrm{C}$ & C3-D \\
\hline Y.00925 & C4-A & C4-B & $\mathrm{C} 4-\mathrm{C}$ & C4-D \\
\hline \multicolumn{5}{|c|}{ S. bayanus var. uvarum } \\
\hline $\mathrm{Cz}-2$ & B1-A & B1-B & B1-C & B1-D \\
\hline Y.00779 & B2-A & B2-B & B2-C & B2-D \\
\hline
\end{tabular}

Sporulation

Sporulation abilities was checked on acetate agar (glucose $1 \mathrm{~g} \mathrm{l}^{-1}$, potassium chloride $1.8 \mathrm{~g} \mathrm{l}^{-1}$, sodium acetate trihydrate $8.2 \mathrm{~g} \mathrm{l}^{-1}$, yeast extract $2.5 \mathrm{~g} \mathrm{l}^{-1}$, agar $15 \mathrm{~g} \mathrm{l}^{-1}$ ), after incubation in $28^{\circ} \mathrm{C}$ for 7 and 14 days (Yarrow 1998).

\section{Chromosomal DNA analysis}

Chromosomal DNA isolation was conducted using a CHEF Genomic DNA Plug Kit (Bio-Rad, Warsaw, Poland) according to the methods described by Schwartz and Cantor (1984). Chromosomes were separated by pulsed field gel electrophoresis (PFGE) in $0.8 \%$ agarose gel by means of a CHEF-DR II apparatus (Bio-Rad, Warsaw, Poland). Electrophoresis was performed in $0.5 \times \mathrm{TBE}$ buffer $(45 \mathrm{mM}$ Tris, $45 \mathrm{mM}$ boric acid, and $10 \mathrm{mM}$ EDTA; $\mathrm{pH} 8.2$, at $10^{\circ} \mathrm{C}$ ) for $28 \mathrm{~h}$, at $6 \mathrm{~V} \mathrm{~cm}^{-1}$ and linearly growing pulse duration from 110 to $220 \mathrm{~s}$. Separated chromosomes were stained in ethidium bromide solution $\left(0.5 \mu \mathrm{g} \mathrm{ml}^{-1}\right)$. The gel was washed in distilled water and photographed.

The molecular weight of bands was estimated using SigmaGel software (Sigma-Aldrich, Gillingham, UK). The electrophoretic profiles of the segregates were compared to that of the S. cerevisiae YNN295 reference strain.

\section{Ploidy assessment}

Total DNA content was estimated by flow cytometry (Becton-Dickinson FACSCalibur cytometer, BD Biosciences, Erembodegem, Belgium) according to methods given by Hutter and Eipel (1979) and Nadal et al. (1999). Yeast cultures were grown in YGP at $28^{\circ} \mathrm{C}$ until cells reached the stationary phase. Cells were separated $(3,500 \times g, 10 \mathrm{~min})$, suspended in $70 \%$ ethanol, cooled down to $4{ }^{\circ} \mathrm{C}$ and fixed for $30 \mathrm{~min}$ at $-20^{\circ} \mathrm{C}$. After centrifugation $(3,500 \times g, 10 \mathrm{~min})$, approximately $10^{6}$ cells were suspended in $500 \mu 150 \mathrm{mM}$ sodium citrate $(\mathrm{pH} 7.5)$. RNA was removed by RNAse A digestion ( $20 \mathrm{U}$ per $500 \mu \mathrm{l}$ sample) for $2 \mathrm{~h}$ at $37^{\circ} \mathrm{C}$. DNA was stained by propidium iodine ( $5 \mu \mathrm{g}$ per $500 \mu \mathrm{l}$ sample) for $16 \mathrm{~h}$ at $4^{\circ} \mathrm{C}$ in the dark. Propidium iodine fluorescence was recorded on a linear scale. The dominant cell population identified by its forward scatter/side scatter profile was gated and the median fluorescence of the G1 peak was recorded. The results were presented in fluorescence units and converted to relative DNA content. Yeast ploidy was calculated by comparison to the reference $S$. cerevisiae haploids Cm MAT a and Gm MAT $\alpha$ assuming that for reference strains 100 fluorescence units is equal to $1 \mathrm{C}$ and assigned as one set of chromosomes (n). 
Mitochondrial DNA analysis

Restriction analysis of mtDNA was performed according to Querol et al. (1992), Querol and Ramon (1996). Restriction enzyme HinfI (Roche Diagnostic, Basel, Switzerland) was used and separation was conducted in $0.7 \%$ agarose gel, in $0.5 \times$ TBE buffer, at $60 \mathrm{~V}$ for $5 \mathrm{~h}$. Gels were stained in ethidium bromide solution $\left(0.5 \mu \mathrm{g} \mathrm{ml}^{-1}\right)$, washed in distilled water, and photographed.

The molecular weight of bands was estimated using SigmaGel software (Sigma-Aldrich, Gillingham, UK). The mtDNA profiles of the segregates were compared to that of the Lambda DNA Hind III EcoR I digest (Sigma-Aldrich, Gillingham, UK).

\section{Statistical analysis}

Hierarchical cluster analysis was used to estimate the similarity of yeast segregates according to their biochemical, chromosomal DNA, and mtDNA profiles. Outcomes were displayed as binary data, 0 or 1 when the feature was absent or present in the yeast profile, respectively. Yeast segregate similarity was considered to be a function of the number of similar features versus the total number of features. Besides, yeasts revealing a high level of similarity formed clusters. The algorithm for hierarchical clustering was agglomerative and Manhattan distance was used as a measure of similarity between pairs of observations. Distances between clusters were calculated by the unweighted pair group method using averages (UPGMA) (Dạbkowski et al. 1997). In this method, the distance between two clusters is calculated as the average distance between all pairs of objects in the two different clusters. In calculation of percentage similarity values Demontax 1.2 program (written by Peter Halling, Strathclyde University and obtained by his courtesy) was used, and then the values obtained were applied on dendrograms. Cluster hierarchy was presented using a tree structure (dendrogram) with horizontal agglomeration distance. Agglomeration analysis was performed by means of Statistica 6.0 software (Tusla, Oklahoma, USA).
Generation times were presented as mean values of three separate experiments with standard deviation.

Total DNA content was given as mean values of three separate experiments with standard deviation. Data were analyzed by WinMDI 2.8 software.

\section{Results and discussion}

General characteristics of wild yeasts

The majority of the tested wine yeasts were classified as aneuploidal according to their DNA content, while only S. cerevisiae Syrena and S. bayanus var. uvarum $\mathrm{Cz}-2$ were diploidal (Table 2). These results are consistent with the findings of Martinez et al. (1995), showing a predominance of aneuploidal strains among wine yeast populations. All the strains revealed sporulation ability, forming 2-4 spores. According to literature data, the ability of wine yeasts to sporulate varies, with aneuploidal strains revealing poor sporulation: if they sporulate at all, they usually produce 2 spores (Castrejon et al. 2004). It is believed that the limited reproduction ability is favored during natural selection, and the fermentative environment is dominated by aneuploidal, homothallic, and apomictic strains (Castrejon et al. 2004). However, data about the sterility of aneuploidal strains and the limited sporulation ability of wine yeasts are not fully consistent with the results of this study.

Saccharomyces cerevisiae strains significantly varied in terms of their biochemical profiles (from 2 to 8 different features), while $S$. bayanus var. uvarum differed in 4 features (data not presented). Surprisingly, in accordance with taxonomy (Barnett et al. 2000), only Y.00779 yeast classified as $S$. bayanus var. uvarum had a biochemical profile typical of $S$. cerevisiae. It may be misleading to assume that the characteristic feature of $S$. bayanus is its ability to ferment melibiose and inability to ferment galactose (Naumov et al. 1993). None of the examined strains fermented melibiose, while the $\mathrm{Gal}^{-}$phenotype was found only in the strain $S$. bayanus var. uvarum $\mathrm{Cz}-2$. Similar

Table 2 Genetic characterization of wine yeast

\begin{tabular}{lllllll}
\hline Features & \multicolumn{2}{l}{ S. cerevisiae } & & & \multicolumn{2}{c}{ S. bayanus var. uvarum } \\
\cline { 2 - 5 } \cline { 5 - 6 } & Syrena & W-13 & Y.00911 & Y.00925 & Cz-2 & Y.00779 \\
\hline Total DNA (n) & $1.36 \pm 0.04$ & $2.03 \pm 0.06$ & $2.15 \pm 0.03$ & $2.23 \pm 0.03$ & $2.06 \pm 0.16$ & $1.48 \pm 0.06$ \\
Ploidy & Aneuploid & Diploid & Aneuploid & Aneuploid & Diploid & Aneuploid \\
Number of spores & $2-4$ & $2-4$ & $2-4$ & $2-4$ & $2-4$ \\
Chromosomal DNA size (kb) & $200-2,200$ & $200-2,200$ & $225-1,600$ & $220-2,200$ & $225-1,825$ & $225-2,275$ \\
Chromosomal DNA bands (number) & 14 & 13 & 11 & 13 & 12 & 16 \\
Mitochondrial DNA size (bp) & $694-5,205$ & $564-5,148$ & $564-1,584$ & $564-6,590$ & $564-5,200$ & $564-8,426$ \\
Mitochondrial DNA bands (number) & 17 & 16 & 5 & 12 & 14 & 16 \\
\hline
\end{tabular}


results have been reported previously (Fernández-Espinar et al. 2001; Molnar et al. 1995; Sabaté et al. 1998) pointing out the possibility of misclassification of yeast strains mainly relying on their phenotypic characters. As proposed in other studies, melibiose and mannitiol utilization could distinguish $S$. cerevisiae from $S$. uvarum/S. bayanus (Vaughan-Martini and Martini 1993) but this phenotypic pattern was also not expressed by every isolates of wine yeasts $S$. cerevisiae and S. uvarum (Csoma et al. 2010).

According to our previous study (Rajkowska and Kunicka 2005), the electrophoretic profiles of chromosomal DNA indicated genomic DNA polymorphism, while karyotyping was insufficient to unequivocally distinguish S. cerevisiae Syrena and $\mathrm{W}-13$ as well as separate $S$. bayanus strains. At the same time, the karyotypes of S. cerevisiae Y.00911, Y.00925 and S. bayanus var. uvarum Y.00779 revealed three bands in the small-sized chromosome 225-365 kb region (Rajkowska and Kunicka 2005), which had been considered characteristic only of S. cerevisiae (Naumov et al. 2000; Tosi et al. 2009). Moreover, S. bayanus var. uvarum Y.00779 had a group of mediumsize chromosomes (450-680 kb) recognized as characteristic of S. bayanus (Sipiczki et al. 2001; Csoma et al. 2010). Opinions on whether strains can be allocated to species based on karyotypes vary substantially, but most researchers believe that it is impossible to distinguish between yeast species within the Saccharomyces sensu stricto complex exclusively on the basis of the presence of a single band or set of bands (Fernández-Espinar et al. 2001; Rainieri et al. 2003; Csoma et al. 2010), which remains consistent with our data. Restriction analysis of wine yeast mtDNA has made it possible to distinguish between all the examined strains, being a better discriminative tool then karyotyping (Rajkowska and Kunicka 2005).

\section{Generation times of yeast segregates}

Generation times of the wine yeasts (data not presented) and their segregates changed depending on the culture conditions (Tables 3,4) but generally were even up to three times longer for yeasts growing in the media with an elevated glucose concentration and L-malic acid presence. Literature data concerning the response of wine yeasts to the acidity of the environment show differences within the Saccharomyces sensu stricto complex. While some authors proved the sensitivity of $S$. cerevisiae wine strains to acidic stress (Fleet and Heard 1993), others showed that low pH did not significantly influence the growth or the fermentative activity of $S$. bayanus var. uvarum (Serra et al. 2005). These discrepant findings can be attributed to the fact that yeast resistance to stresses varies from strain to strain (Carrasco et al. 2001; de Melo et al. 2010) and it is also reflected in different responds of the tested strains $S$. cerevisiae (e.g. Syrena versus Y.00925) and S. bayanus (Cz-2 versus Y.00779).

The generation times of segregates reached in YGP medium were about $29-62 \%$ longer in aerobic conditions than under fermentation (Tables 3, 4). On the contrary, the generation times estimated in YG medium with L-malic acid not differ very much between aerobic and semi-anaerobic conditions. In the course of fermentation, due to an excess of cytoplasmic NADH, S. cerevisiae are subjected to a reductive stress minimized by glycerol production (Albers et al. 1998, Valadi et al. 2004). Valadi et al. (2004) show that yeasts with deletions of GPD2 and TDH1 genes (encoding glycerol 3-phosphate-dehydrogenase and glyceraldehyde-3-phosphate dehydrogenase, respectively) improved their anaerobic growth by shortening the generation time by $1 / 9$ comparing to aerobic conditions. The genetic manipulations of GPD2 gene also decreased a glycerol production, so the excess carbon was redirected to biomass, resulting in significant increase in the specific growth rate in anaerobiosis (Hou and Vemuri 2010). Variable generation times of the wild and evolved yeasts tested by us may be a result of differences in expression of genes involved in glycerol metabolism, however multidirectional genome alterations under reductive stress cannot be excluded. Moreover, the combined glucose, acidic and reductive stresses (in YG medium) probably affected yeast growth more extensively than oxygen shortage. The karyotyping and mtDNA restriction analysis only show gross structural changes in the chromosomes and changes in mitochondrial DNA, respectively. Many other DNA changes that cannot be analyzed by those techniques may have occurred in the evolved strains (e.g. SNPs-single-nucleotide polymorphism) and could be related with their biochemical changes.

Biochemical profiles of yeasts and their segregates

Changes in the biochemical profiles of $S$. cerevisiae varied independently of culture conditions (Tables 3, 4). Yeast strains expressed a tendency to expand the range of compounds used as sole carbon sources. The highest stability of biochemical features was observed for glucose, galactose, maltose, sucrose and melibiose fermentation as well as for glycerol and nitrate assimilation. The most vivid changes concerned 9 compounds: lactose, inositol, $\mathrm{N}$-acetyl-D-glucosamine, sorbitol, adonitol, 2-keto-D-gluconate, melezitose, trehalose and xylitol. Both S. bayanus var. uvarum strains revealed considerable changes in the biochemical profiles of their semi-anaerobic segregates under glucose and acidic stress (Table 4), which made them much more similar to $S$. cerevisiae strains than to their own wild ones. A dendrogram of biochemical profile similarity drawn for wild yeast and their segregates (Fig. 1) shows a clear division into two clusters: $S$. cerevisiae (22 strains) and $S$. 
Table 3 Changes of wine yeast in aerobic conditions

\begin{tabular}{|c|c|c|c|c|c|c|}
\hline \multirow[t]{2}{*}{ Features } & \multicolumn{4}{|l|}{ S. cerevisiae } & \multicolumn{2}{|c|}{ S. bayanus var. uvarum } \\
\hline & Syrena & $\mathrm{W}-13$ & Y.00911 & Y.00925 & $\mathrm{Cz}-2$ & Y.00779 \\
\hline \multicolumn{7}{|l|}{ YGP } \\
\hline Generation time (min) & $94.3 \pm 2.5$ & $88.2 \pm 2.0$ & $78.4 \pm 1.6$ & $77.2 \pm 1.2$ & $78.0 \pm 1.8$ & $147.8 \pm 2.1$ \\
\hline Number of generations & $129 \pm 4$ & $138 \pm 3$ & $156 \pm 3$ & $158 \pm 2$ & $156 \pm 4$ & $83 \pm 1$ \\
\hline $\begin{array}{l}\text { Assimilation differences } \\
\text { (number) }\end{array}$ & 2 & 3 & 6 & 0 & 0 & 2 \\
\hline $\begin{array}{l}\text { Fermentation differences } \\
\text { (number) }\end{array}$ & 0 & 1 & 2 & 1 & 0 & 0 \\
\hline Total DNA (n) & $1.42 \pm 0.04$ & $1.93 \pm 0.08$ & $1.88 \pm 0.03$ & $2.37 \pm 0.05$ & $2.08 \pm 0.07$ & $1.42 \pm 0.04$ \\
\hline Ploidy & Aneuploid & Diploid & Aneuploid & Aneuploid & Diploid & Aneuploid \\
\hline Number of spores & $2-4$ & $2-4$ & $2-4$ & $2-4$ & $2-4$ & $2-4$ \\
\hline $\begin{array}{l}\text { Different bands }{ }^{\mathrm{a}} \text { of } \\
\text { chromosomal DNA size } \\
(\mathrm{kb})\end{array}$ & - & - & 2,200 & $\begin{array}{l}2,200^{*}, 1,300 \\
\quad 600\end{array}$ & 2,050 & $1,825^{*}, 975$ \\
\hline $\begin{array}{l}\text { Different bands } \mathrm{s}^{\mathrm{a}} \text { of } \\
\text { mitochondrial DNA size } \\
\text { (bp) }\end{array}$ & - & - & $\begin{array}{l}4,557,4,234,3,328 \\
3,033,2,581,2,260 \\
1,880,1,680,1,117 \\
817\end{array}$ & - & - & - \\
\hline \multicolumn{7}{|l|}{ YG + L-malic acid } \\
\hline Generation time (min) & $96.5 \pm 1.9$ & $111.1 \pm 1.7$ & $93.6 \pm 2.2$ & $94.5 \pm 0.8$ & $127.8 \pm 2.2$ & $147.5 \pm 2.6$ \\
\hline Number of generations & $124 \pm 2$ & $108 \pm 2$ & $128 \pm 3$ & $127 \pm 1$ & $94 \pm 2$ & $81 \pm 2$ \\
\hline $\begin{array}{l}\text { Assimilation differences } \\
\text { (number) }\end{array}$ & 2 & 3 & 6 & 1 & 0 & 2 \\
\hline $\begin{array}{l}\text { Fermentation differences } \\
\text { (number) }\end{array}$ & 0 & 0 & 2 & 1 & 0 & 0 \\
\hline Total DNA (n) & $1.42 \pm 0.05$ & $1.79 \pm 0.04$ & $1.97 \pm 0.04$ & $2.24 \pm 0.01$ & $2.20 \pm 0.04$ & $1.35 \pm 0.05$ \\
\hline Ploidy & Aneuploid & Aneuploid & Diploid & Aneuploid & Aneuploid & Aneuploid \\
\hline Number of spores & $2-4$ & $2-4$ & $2-4$ & $2-4$ & $2-4$ & $2-4$ \\
\hline $\begin{array}{l}\text { Different bands }{ }^{\mathrm{a}} \text { of } \\
\text { chromosomal DNA size } \\
(\mathrm{kb})\end{array}$ & - & - & 2,200 & - & 1,450 & $\begin{array}{l}1,825^{*}, 1,150^{*} \\
\quad 975\end{array}$ \\
\hline $\begin{array}{l}\text { Different bands } \mathrm{s}^{\mathrm{a}} \text { of } \\
\text { mitochondrial DNA size } \\
\text { (bp) }\end{array}$ & - & - & $\begin{array}{l}4,557,4,234,3,328 \\
3,033,2,581,2,260 \\
1,880,1,680,1,117 \\
817\end{array}$ & - & $\begin{array}{l}3,275,1,965^{*} \\
\quad 947^{*}\end{array}$ & - \\
\hline
\end{tabular}

* Disappearing bands, bands without asterisk-additional bands

${ }^{a}$ Different bands comparing to wild strains

bayanus (8 strains). Generally, malic acid did not influence changes in the biochemical profiles of $S$. cerevisiae grown under either aerobiosis or anaerobiosis, or S. bayanus grown under aerobiosis. Changes in the biochemical characteristics of Saccharomyces sensu stricto yeasts, concerning both the acquisition and loss of some characteristics, have been previously reported (Rosini et al. 1982). The appearance or lost of some features and the segregation of one during vegetative growth can be explained by gene polymorphism and occasional silencing and reactivation of the corresponding genes (Turakainen et al. 1993, Csoma et al. 2010). This behavior was previously observed for $\mathrm{Mel}^{-}$isolates of wine yeasts $S$. cerevisiae producing $\mathrm{Mel}^{+}$segregates (Csoma et al. 2010) and S. bayanus strain containing the silent sequence $\mathrm{MEL}^{0}$ reverting to the $\mathrm{Mel}^{+}$ segregates (Turakainen et al. 1993). Csoma et al. (2010) also mentioned similar diversity in copper-resistant phenotypes. Changes in morphological, physiological, and biochemical properties were also found during long-term storage of collection strains (Miklos et al. 1997). The significance of the impact of spontaneous mutations is disputable because of their very low rates (Querol et al. 2003), but their role in genetic alterations can be considered together with mitotic crossing over gene conversion (Puig et al. 2000). However S. bayanus/uvarum yeasts are considered to be more stable than most of the $S$. cerevisiae wine strains, the segregation of some traits in both species implying genome changes during vegetative propagation 


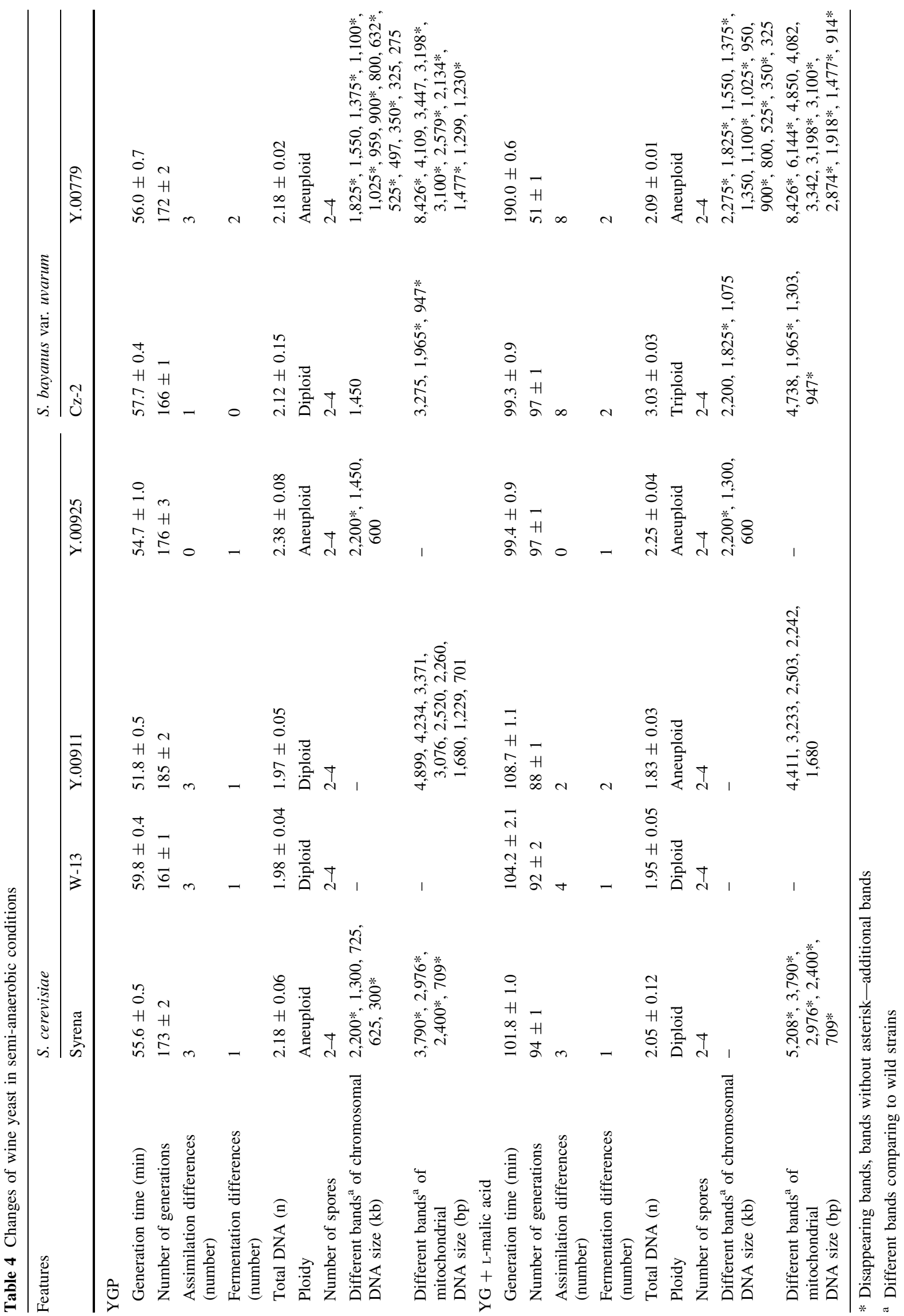


was previously noted (Csoma et al. 2010). The high diversity of $S$. bayanus var. uvarum strains tested by us was probably due to strain-specificity as it can be seen even comparing biochemical and genetic changes of $\mathrm{Cz}-2$ and Y.00779. The changes in the phenotypes of $S$. bayanus segregates, observed in a medium similar to the natural fermentation environment, can be also explained by the selection of best-suited subpopulations.

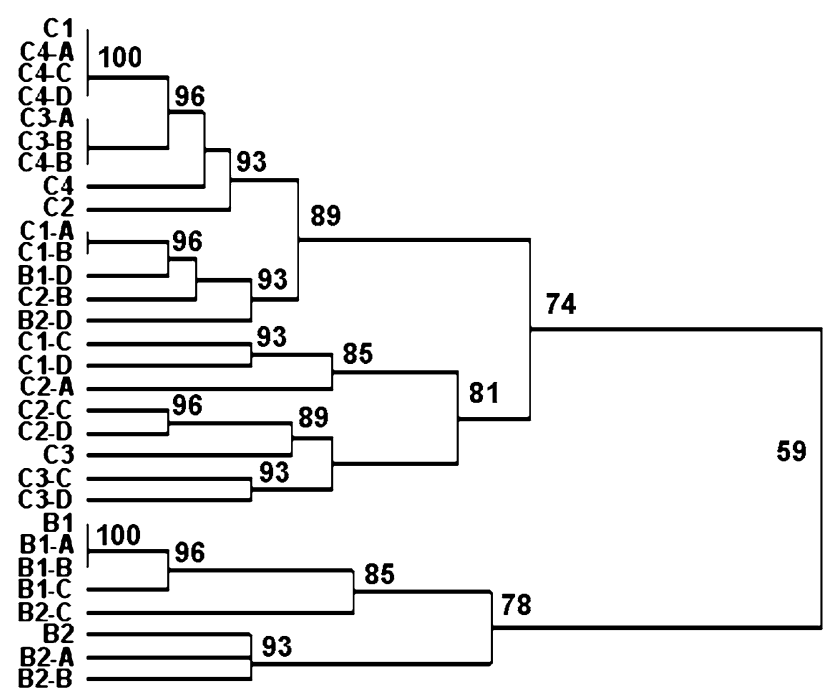

Fig. 1 Dendrogram of biochemical profiles similarity of wine yeasts: C1, S. cerevisiae Syrena; C1-A-C1-D, segregates of Syrena; C2, S. cerevisiae W-13; C2-A-C2-D, segregates of W-13; C3, S. cerevisiae Y.00911; C3-A-C3-D, segregates of Y.00911; C4, S. cerevisiae Y.00925; C4-A-C4-D, segregates of Y.00925; B1-S. bayanus var. uvarum $\mathrm{Cz}-2$; B1-A-B1-D, segregates of $\mathrm{Cz}-2$; B2, S. bayanus var. uvarum Y.00779; B2-A-B2-D, segregates of Y.00779; A-YGP, aerobic conditions; $\mathrm{B}-\mathrm{YG}+\mathrm{L}-\mathrm{malic}$ acid, aerobic conditions; C-YGP, semi-anaerobic conditions; D-YG + L-malic acid, semianaerobic conditions
Changes in chromosomal DNA and ploidy

Generally, S. cerevisiae Syrena and W-13 were characterized by stable chromosomal DNA irrespective of the acidity of the growth environment (Tables 3, 4). Some changes in band number and location have been observed for the Syrena segregate only after anaerobic passages in a medium without L-malic acid. The other two $S$. cerevisiae strains revealed karyotype changes that seem to be specific to the strains and independent of culture conditions (Fig. 2). The greatest changes in the number and intensity of bands were observed in the DNA profiles of $S$. bayanus var. uvarum Y.00779 semi-anaerobic segregates (differences in 14-15 bands), Table 4, Fig. 2. Hierarchical cluster analysis of yeast karyotypes led to defining one homogeneous group of strains, consisting of $S$. cerevisiae Syrena and $\mathrm{W}-13$, S. bayanus var. uvarum $\mathrm{Cz}-2$ and their segregates, as well as the S. bayanus var. uvarum Y.00779 semianaerobic segregate (Fig. 3). Our results are consistent with literature data, notifying significant variability in the number and size of chromosomes in wine yeast clones (Miklos et al. 1997). Wine yeasts tend to express a high level of chromosomal length polymorphism (Bidenne et al. 1992; Rachidi et al. 1999), which can contribute to the observed changes in karyotypes. Researches of wine yeast genome have reported both interchromosomal (translocation) and intrachromosomal (deletion and duplication) changes, or the presence of a variable number of chromosomes with high or low homology (Bidenne et al. 1992; Guerra et al. 2001; Vezinhet et al. 1990), which is reflected in chromosomal DNA profiles. Our results confirm that there occur considerable changes in the karyotypes of wine yeasts under semi-anaerobic conditions, which suggests greater genome plasticity under fermentative stress.
Fig. 2 Electrophoretic profiles of chromosomal DNA; C2, $S$. cerevisiae $\mathrm{W}-13$; $\mathrm{C} 2-\mathrm{A}-\mathrm{C} 2-\mathrm{D}$, segregates of $\mathrm{W}-13 ; \mathrm{C} 3, \mathrm{~S}$. cerevisiae $\mathrm{Y} .00911$; $\mathrm{C} 3-\mathrm{A}-\mathrm{C} 3-$ D, segregates of Y.00911; B2, S. bayanus var. uvarum Y.00779; B2-A-B2-D, segregates of $S$. bayanus var. uvarum Y.00779; A-YGP, aerobic conditions; BYG + L-malic acid, aerobic conditions; C-YGP, semianaerobic conditions; DYG + L-malic acid, semianaerobic conditions; $\mathrm{M}-$ molecular marker $S$. cerevisiae YNN295
C2 C2-A C2-B C2-C C2-D

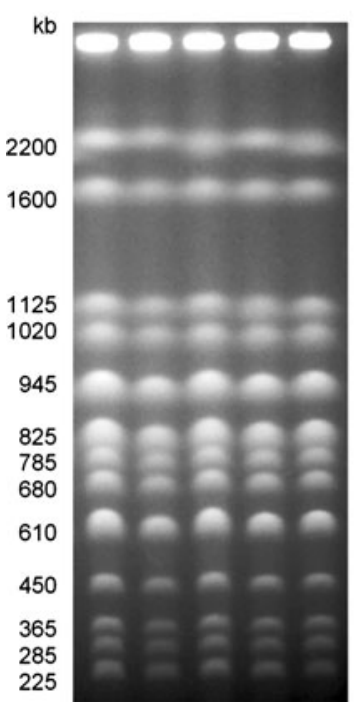

M C3 C3-A C3-B C3-C C3-D

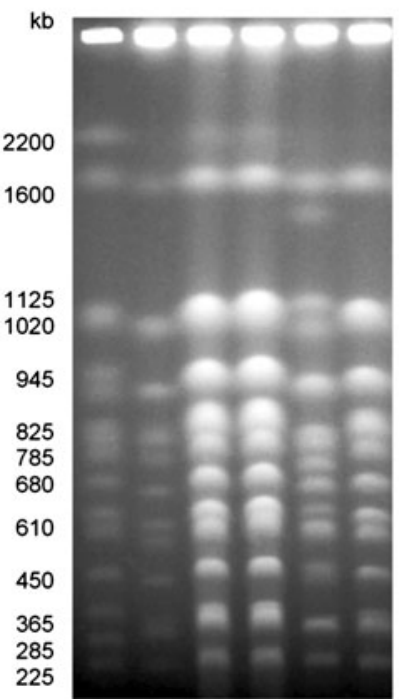

B2 B2-A B2-B B2-C B2-D

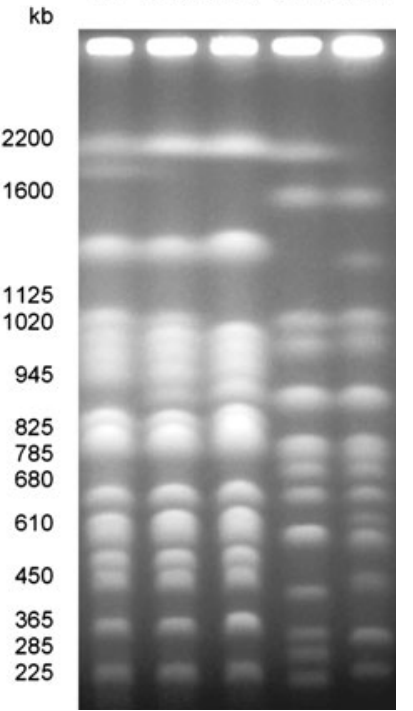




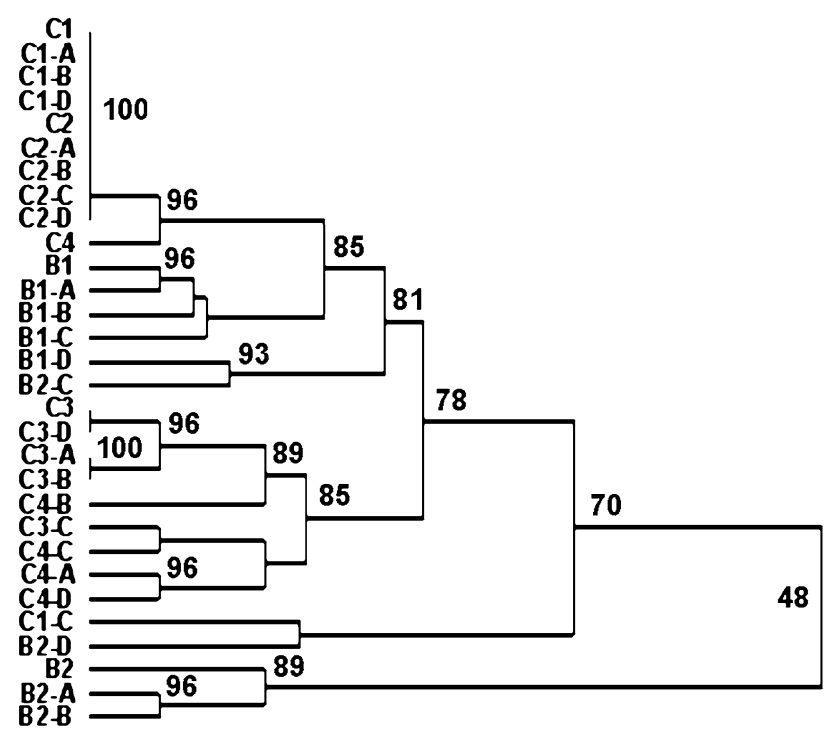

Fig. 3 Dendrogram of chromosomal DNA profiles similarity of wine yeasts: C1, S. cerevisiae Syrena; C1-A-C1-D, segregates of Syrena; C2, S. cerevisiae W-13; C2-A-C2-D, segregates of W-13; C3, S. cerevisiae Y.00911; C3-A-C3-D, segregates of Y.00911; C4, S. cerevisiae Y.00925; C4-A-C4-D, segregates of Y.00925; B1-S. bayanus var. uvarum $\mathrm{Cz}-2$; B1-A-B1-D, segregates of $\mathrm{Cz}-2$; B2, $S$. bayanus var. uvarum Y.00779; B2-A-B2-D, segregates of Y.00779; $\mathrm{A}-\mathrm{YGP}$, aerobic conditions; $\mathrm{B}-\mathrm{YG}+\mathrm{L}-\mathrm{malic}$ acid, aerobic conditions; $\mathrm{C}-\mathrm{YGP}$, semi-anaerobic conditions; $\mathrm{D}-\mathrm{YG}+\mathrm{L}-\mathrm{malic}$ acid, semi-anaerobic conditions

Considering the low rates of spontaneous mutations, recombination between homologous chromosomes as well as mitotic recombination during vegetative growth may have a greater impact on karyotype variability (Nadal et al. 1999; Puig et al. 2000).

Acidic stress has not been found to bear significantly on yeast karyotypes either under aerobic or semi-anaerobic conditions. Literature data concerning the effect of malate on wine yeasts was discussed in Generation times of yeasts segregates section. In our study, neither $S$. cerevisiae nor $S$. bayanus showed any substantial changes in chromosomal DNA that could be attributed to the presence of L-malic acid, which is consistent with the findings of Belloch et al. (2008) for the Saccharomyces sensu stricto group. Anyway, considering the changes in generation times of segregates, the effect of L-malic acid on yeast metabolism with the corresponding chromosomal DNA changes at the molecular level cannot be excluded (Redzepovic et al. 2003).

All segregates preserved their sporulation ability but changes in ploidy were found to reach $47 \%$. However, the changes in ploidy were not strictly correlated with the extent of changes in chromosomal DNA, and reached about $12 \%$ even for the genotypically stable $S$. cerevisiae W-13 (Tables 2, 3, 4). Similarly to our study, differences in the ploidy of Saccharomyces yeasts have been detected in strains with identical nuclear and mitochondrial DNA sequences (Spirek et al. 2003). At the same time, it should be remembered that DNA content in a cell may result from the monosomy, disomy or polysomy of single chromosomes (Ibeas and Jimenez 1996) and is not necessarily connected with the duplication of chromosome sets. Aneuploidy and polyploidy can ensure an advantage in adapting to the variable environment or increase the gene pool important for fermentation (Querol et al. 2003; Salmon 1997). Aneuploidal and polyploidal strains gain an advantage in natural selection conditions in respect of such characteristics as ethanol production, fast and efficient fermentation, and tolerance to high ethanol and sulfur dioxide concentrations (Guijo et al. 1997). Additionally, aneuploidy or polyploidy may protect the yeasts against spontaneous recessive mutations of lethal consequences (Tavares et al. 1988).

\section{Changes in mitochondrial DNA}

The mitochondrial DNA profiles of $S$. cerevisiae $\mathrm{W}-13$ and Y.00925 segregates remained unchanged irrespective of growth conditions (Tables 3, 4). Substantial changes in the mtDNA of the other strains were observed mainly under fermentation. The only exceptions were $S$. cerevisiae Y.00911 segregates-from 5 to 10 additional bands appeared in their electrophoretic patterns after cultivation under any conditions tested (Fig. 4). The greatest changes in mtDNA were observed for the semi-anaerobic segregates of S. bayanus var. uvarum Y.0079. The dendrogram of mtDNA similarity revealed substantial heterogeneity of the yeasts, except for identical segregates of the same strains (Fig. 5). Restriction analysis of mitochondrial DNA is considered a good discriminative tool for estimating wine yeast differentiation (Fernández-Espinar et al. 2001; Muňoz et al. 2009; Nadal et al. 1996), which is consistent with our findings. In this study, segregates with stable chromosomal DNA reveal also an unchanged mtDNA electrophoretic profile, which indicates that the yeasts are stable under the particular test conditions. At the same time, karyotype changes have not always been correlated with mtDNA changes, which can be explained by differences in inheritance of mitochondrial and nuclear DNA (Groth et al. 2000). Generally, the greatest changes in mtDNA profiles were found under fermentation, which may be due to the fact that mitochondrial metabolism under aerobic and anaerobic conditions is quite different (Dejean et al. 2000). It may reflect the lesser role of respiration under anaerobiosis allowing mitochondrial changes to be maintained in the population. Rearrangements in mitochondrial DNA are not affected by elevated L-malic acid content. 

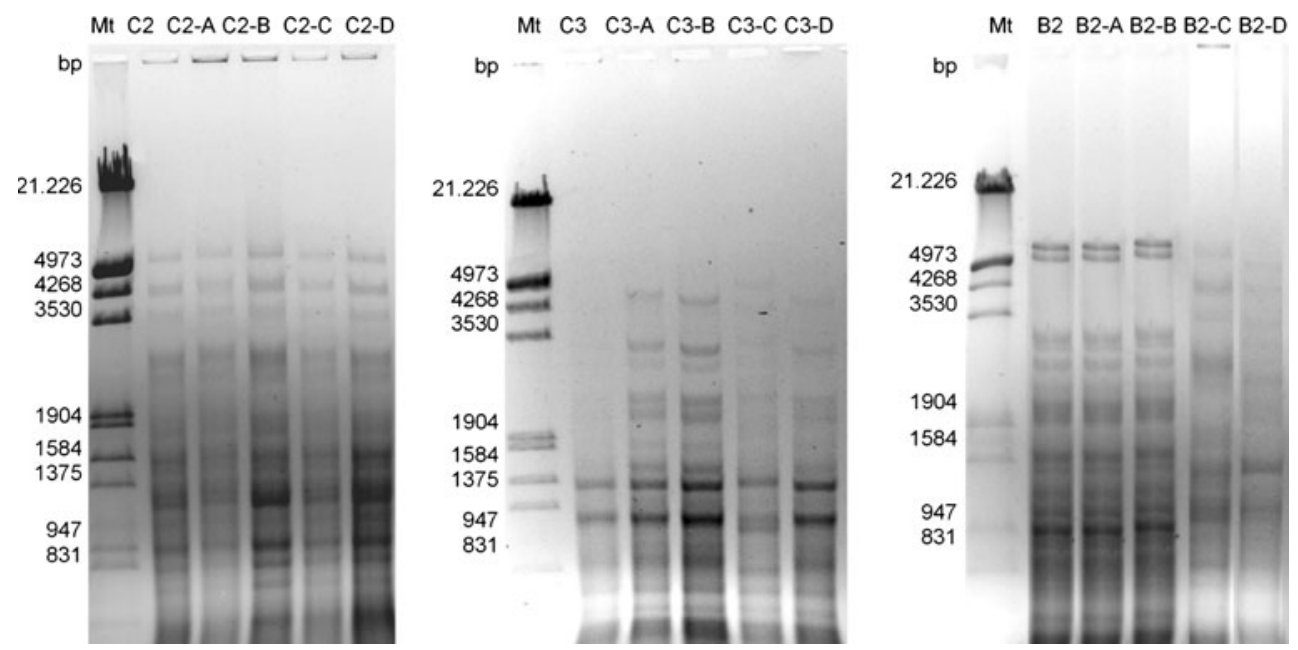

Fig. 4 Electrophoretic profiles of mitochondrial DNA; C2, S. cerevisiae $\mathrm{W}-13$; C2-A-C2-D, segregates of $\mathrm{W}-13$; C3, S. cerevisiae Y.00911; C3-A-C3-D, segregates of Y.00911; B2, S. bayanus var. uvarum Y.00779; B2-A-B2-D, segregates of S. bayanus var. uvarum

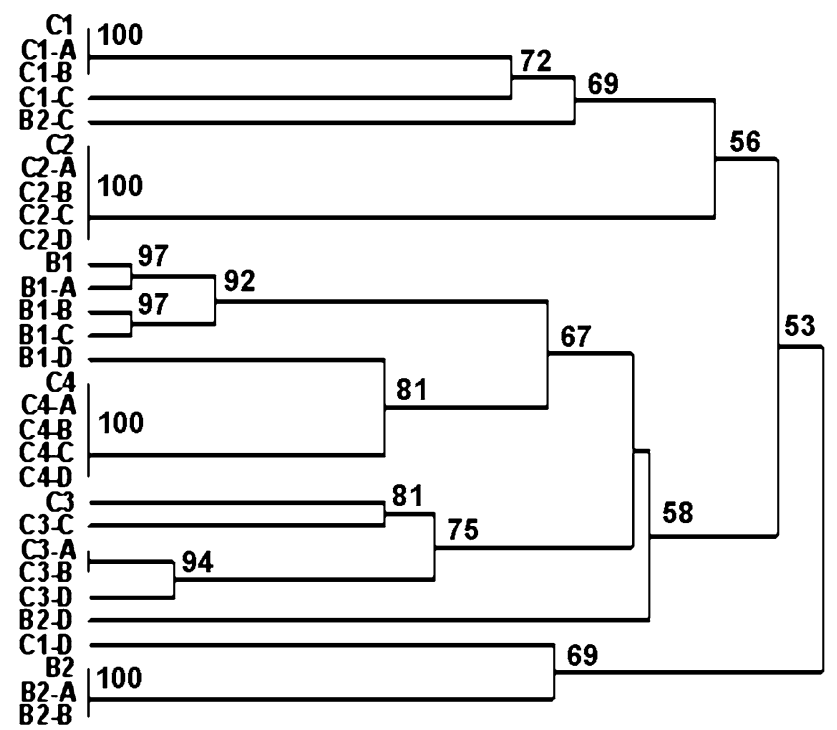

Fig. 5 Dendrogram of mtDNA profiles similarity of wine yeasts: $\mathrm{C} 1$, $S$. cerevisiae Syrena; C1-A-C1-D, segregates of Syrena; C2, S. cerevisiae $\mathrm{W}-13$; C2-A-C2-D, segregates of $\mathrm{W}-13$; C3, S. cerevisiae Y.00911; C3-A-C3-D, segregates of Y.00911; C4, S. cerevisiae Y.00925; C4-A-C4-D, segregates of Y.00925; B1-S. bayanus var. uvarum $\mathrm{Cz}-2$; B1-A-B1-D, segregates of $\mathrm{Cz}-2$; B2, S. bayanus var. uvarum Y.00779; B2-A-B2-D, segregates of Y.00779; A-YGP, aerobic conditions; $\mathrm{B}-\mathrm{YG}+\mathrm{L}-\mathrm{malic}$ acid, aerobic conditions; $\mathrm{C}-$ YGP, semi-anaerobic conditions; D-YG + L-malic acid, semianaerobic conditions

\section{Conclusions}

Wine yeasts demonstrate considerable genome plasticity, which predisposes them for fast adaptive changes allowing them to survive in a constantly varying fermentation environment. Our study proves that among the yeasts
Y.00779; A-YGP, aerobic conditions; $\mathrm{B}-\mathrm{YG}+\mathrm{L}-\mathrm{malic}$ acid, aerobic conditions; $\mathrm{C}-\mathrm{YGP}$, semi-anaerobic conditions; $\mathrm{D}-$ YG + L-malic acid, semi-anaerobic conditions; Mt-molecular marker Lamba DNA Lambda DNA Hind III EcoR I digest

typically used in winemaking there are both strains expressing very high stability in both chromosomal and mitochondrial DNA ( $S$. cerevisiae $\mathrm{W}-13$ ) as well as labile strains, such as $S$. cerevisiae Y.00911 and S. bayanus var. uvarum Y.00779. Changes in karyotypes and mitochondrial DNA profiles, mostly observed under fermentation, confirm that fermentative stress is the main driving force in yeast adaptive evolution. The fact that L-malic acid does not influence the extent of genomic changes indicates that the resistance of wine yeasts exhibiting increased demalication activity to acidic stress may be related to their ability to decompose this acid. The same phenomenon has been found for the much more genotypically labile intraspecific and interspecific hybrids of these yeasts (Kunicka-Styczyńska and Rajkowska 2011). Phenotypic changes of segregates, detected even in those yeasts which do not reveal deviations in DNA profiles, prove that phenotypic characterization may be misleading in wine yeast identification. Significant changes in biochemical profiles are not always correlated with the genomic modifications detected with universally used methods such as karyotyping and mtDNA restriction analysis. Because of frequent length polymorphism and aneuploidy (gross genomic diversity), karyotyping even though it does not seem to be a good discriminative tool, can be successfully used to determine the stability of wine yeasts. Restriction analysis of mitochondrial DNA seems to be a more sensitive technique allowing for an early detection of genotypic changes in yeast. A combination of both methods makes it possible to conduct the quick routine assessment of wine yeast stability in pure culture collections depositing industrial strains. The segregates of wine yeasts obtained in our study provide suitable material for researching the adaptive 
evolution of wine yeasts subjected to fermentative stress. The stability of their technological features during wine must fermentation will be explored in further studies.

Acknowledgments The authors would like to thank two anonymous referees for their suggestions which greatly improved the original version of the article.

Open Access This article is distributed under the terms of the Creative Commons Attribution Noncommercial License which permits any noncommercial use, distribution, and reproduction in any medium, provided the original author(s) and source are credited.

\section{References}

Albers E, Liden G, Larsson C, Gustafsson L (1998) Anaerobic redox balance and nitrogen metabolism in Saccharomyces cerevisiae. Rec Dev Microbiol 2:253-279

Barnett JA, Payne RW, Yarrow D (2000) Yeasts: characteristics and identification, 3rd edn. Cambridge University Press, Cambridge

Belloch C, Orlic S, Barrio E, Querol A (2008) Fermentative stress adaptation of hybrids within the Saccharomyces sensu stricto complex. Int J Food Microbiol 122:188-195. doi:10.1016/ j.ijfoodmicro.2007.11.083

Bidenne C, Blondin B, Dequin S, Vezinhet F (1992) Analysis of the chromosomal DNA polymorphism of wine strains of Saccharomyces cerevisiae. Curr Genet 22:1-7. doi:10.1007/BF00351734

Bradbury JE, Richards KD, Niederer HA, Lee SA, Dunbar PR, Gardner RC (2006) A homozygous diploid subset of commercial wine yeast strains. Antonie van Leeuwenhoek 89:27-37. doi:10.1007/s10482-005-9006-1

Cardona F, Carrasco P, Pérez-Ortín JE, del Olmo M, Aranda A (2007) A novel approach for the improvement of stress resistance in wine yeasts. Int J Food Microbiol 114:83-91. doi:b10.1016/ j.ijfoodmicro.2006.10.043

Carrasco P, Querol A, Del Olmo M (2001) Analysis of stress resistance of commercial wine yeast strains. Arch Microbiol 175:450-457. doi:10.1007/s002030100289

Castrejon F, Martinez-Force E, Benitez T, Codon AC (2004) Genetic analysis of apomictic wine yeasts. Curr Genet 45:187-196. doi:10.1007/s00294-004-0486-8

Csoma H, Zakany N, Capece A, Romano P, Sipiczki M (2010) Biological diversity of Saccharomyces yeasts of spontaneously fermenting wines in four wine regions: comparative genotypic and phenotypic analysis. Int J Food Microbiol 140:239-248. doi:10.1016/j.ijfoodmicro.2010.03.024

Dąbkowski J, Demski T, Iwasiewicz A, Jakubowski J, Lesińska E, Pietraszek J, Polański Z, Sokołowski A, Stefanów P, Wątroba J (1997) Statistica Pl for Windows-podręcznik. StatSoft, Kraków, pp 1556-1558

de Melo HF, Bonini BM, Thevelein J, Simões DA, Morais MA Jr (2010) Physiological and molecular analysis of the stress response of Saccharomyces cerevisiae imposed by strong inorganic acid with implication to industrial fermentations. J Appl Microbiol 109:116-127. doi:10.1111/j.13652672.2009.04633.x

Dejean L, Beauvoit B, Guerin B, Rigoulet M (2000) Growth of the yeast Saccharomyces cerevisiae on a non-fermentable substrate: control of energetic yield by the amount of mitochondria. Biochim Biophys Acta 1457:45-56. doi:10.1016/S00052728(00)00053-0
Fernández-Espinar MT, López V, Ramón D, Bartra E, Querol A (2001) Study of the authenticity of commercial wine yeast strains by molecular techniques. Int J Food Microbiol 70:1-10. doi:10.1016/S0168-1605(01)00502-5

Fleet GH, Heard GM (1993) Yeasts-growth during fermentation. In: Fleet GH (ed) Wine microbiology and biotechnology. Harwood Academic Publishers, Chur, pp 42-43

Fox MS (1998) Some recollections and reflections on mutation rates. Genetics 148:1415-1418

Gonzalez SS, Barrio E, Gafner J, Querol A (2006) Natural hybrids from Saccharomyces cerevisiae, Saccharomyces bayanus and Saccharomyces kudriavzevii in wine fermentations. FEMS Yeast Res 6:1221-1234. doi:10.1111/j.1567-1364.2006.00126.x

Gonzalez SS, Gallo L, Climent D, Barrio E, Querol A (2007) Enological characterization of natural hybrids from $S$. cerevisiae and S. kudriavzevii. Int J Food Microbiol 116:111-118. doi:10.1016/j.ijfoodmicro.2006.10.047

Groth C, Petersen RF, Piskur J (2000) Diversity in organization and the origin of gene orders in the mitochondrial DNA molecules of the genus Saccharomyces. Mol Biol Evol 17:1833-1841

Guerra JB, Araújo RAC, Pataro C, Franco GR, Moreira ESA, Mendonça-Hagler LC, Rosa CA (2001) Genetic diversity of Saccharomyces cerevisiae strains during the $24 \mathrm{~h}$ fermentative cycle for the production of the artisanal Brazilian cachaça. Lett Appl Microbiol 33:106-111. doi:10.1046/j.1472765x.2001.00959.x

Guijo S, Mauricio JC, Salmon JM, Ortega JM (1997) Determination of the relative ploidy in different Saccharomyces cerevisiae strains used for fermentation and 'flor' film ageing of dry sherrytype wines. Yeast 13:101-117. doi:10.1002/(SICI)10970061(199702)13:2<101:AID-YEA66>3.0.CO;2-H

Hou J, Vemuri GN (2010) Using regulatory information to manipulate glycerol metabolism in Saccharomyces cerevisiae. Appl Microbiol Biotechnol 85:1123-1130. doi:10.1007/s00253-0092202-6

Hutter KJ, Eipel HE (1979) Microbial determinations by flow cytometry. J Gen Microbiol 113:369-375. doi:10.1099/ 00221287-113-2-369

Ibeas JI, Jimenez J (1996) Genomic complexity and chromosomal rearrangements in wine laboratory yeast hybrids. Curr Genet 30:410-416. doi:10.1007/s002940050150

Kunicka-Styczyńska A, Rajkowska K (2011) Physiological and genetic stability of hybrids of industrial wine yeasts Saccharomyces sensu stricto complex. J Appl Microbiol 110:1538-1549. doi:10.1111./j.1365-2672.2011.05009.x

Kurtzman CP (2003) Phylogenetic circumscription of Saccharomyces, Kluyveromyces and other members of the Saccharomycetaceae, and the proposal of the new genera Lachancea, Nakaseomyces, Naumovia, Vanderwaltozyma and Zygotorulaspora. FEMS Yeast Res 4:233-245. doi:10.1016/S15671356(03)00175-2

Le Jeune C, Lollier M, Demuyter C, Erny C, Legras J-L, Aigle M, Masneuf-Pomarede I (2007) Characterization of natural hybrids of Saccharomyces cerevisiae and Saccharomyces bayanus var. uvarum. FEMS Yeast Res 7:540-549. doi:10.1111/j.15671364.2007.00207.x

Lopandic K, Gangl H, Wallner E, Tscheik G, Leitner G, Querol A, Borth N, Breitenbach M, Prillinger H, Tiefenbrunner W (2007) Genetically different wine yeasts isolated from Austrian vinegrowing regions influence wine aroma differently and contain putative hybrids between Saccharomyces cerevisiae and Saccharomyces kudriavzevii. FEMS Yeast Res 7:953-965. doi:10.1111/j.1567-1364.2007.00240.x

Lopes CA, Barrio E, Querol A (2010) Natural hybrids of $S$. cerevisiae $\times S$. kudriavzevii share alleles with European wild 
populations of Saccharomyces kudriavzevii. FEMS Yeast Res 10:412-421. doi:10.1111/j.1567-1364.2010.00614.x

Martinez P, Codón AC, Pérez L, Benitez T (1995) Physiological and molecular characterization of flor yeasts: polymorphism of flor yeast populations. Yeast 11:1399-1411. doi:10.1002/yea.320111408

Mesa JJ, Infante JJ, Rebordinos L, Cantoral JM (1999) Characterization of yeast involved in the biological ageing of sherry wines. Food Sci Technol 32:114-120. doi:10.1006/fstl.1998.0514

Miklos I, Varga T, Nagy A, Sipiczki M (1997) Genome instability and chromosomal rearrangements in a heterothallic wine yeast. J Basic Microbiol 37:345-354. doi:10.1002/jobm.3620370507

Molnar O, Messner R, Prillinger H, Stahl U, Slavikova E (1995) Genotypic identification of Saccharomyces species using random amplified polymorphic DNA analysis. Syst Appl Microbiol 18:136-145

Muňoz R, Gómez A, Robles V, Rodriguez P, Cebollero E, Tabera L, Carrascosa AV, Gonzalez R (2009) Multilocus sequence typing of oenological Saccharomyces cerevisiae strains. Food Microbiol 26:841-846. doi:10.1016/j.fm.2009.05.009

Nadal D, Colomer B, Piňa B (1996) Molecular polymorphism distribution in phenotypically distinct populations of wine yeast strains. Appl Environ Microbiol 62:1944-1950

Nadal D, Carro D, Fernández-Larrea J, Piňa B (1999) Analysis and dynamics of the chromosomal complements of wild sparklingwine yeast strains. Appl Environ Microbiol 65:1688-1695

Naumov GI, Naumova ES, Gaillardin C (1993) Genetic and karyotypic identification of wine Sacharomyces bayanus yeasts isolated in France and Italy. Syst Appl Microbiol 16:272-279

Naumov GI, James SA, Naumova ES, Louis EJ, Roberts IN (2000) Three new species in the Saccharomyces sensu stricto complex: Saccharomyces cariocanus, Saccharomyces kudriavzevii and Saccharomyces mikatae. Int J Syst Evol Microbiol 50:1931-1942

Pretorius S, Bauer FF (2002) Meeting the consumer challenge through genetically customized wine-yeast strains. Trends Biotechnol 20:426-432. doi:10.1016/S0167-7799(02)02049-8

Puig S, Querol A, Barrio E, Perez-Ortin JE (2000) Mitotic recombination and genetic changes in Saccharomyces cerevisiae during wine fermentation. Appl Environ Microbiol 66:2057-2061

Querol A, Ramon D (1996) The application of molecular techniques in wine microbiology. Trends Food Sci Technol 7:73-78. doi:10.1016/0924-2244(96)81300-8

Querol A, Barrio E, Ramon D (1992) A comparative study of different methods of yeast strain characterization. Syst Appl Microbiol 15:439-446

Querol A, Fernández-Espinar MT, del Olmo M, Barrio E (2003) Adaptive evolution of wine yeast. Int J Food Microbiol 86:3-10. doi:10.1016/S0168-1605(03)00244-7

Rachidi N, Barre P, Blondin B (1999) Multiple Ty-mediated chromosomal translocation lead to karyotype changes in a wine strain of Saccharomyces cerevisiae. Mol Gen Genet 261:841-850. doi:10.1007/s004380050028

Rainieri S, Zambonelli C, Kaneko Y (2003) Saccharomyces sensu stricto: systematics, genetic diversity and evolution. J Biosci Bioeng 96:1-9. doi:10.1016/S1389-1723(03)90089-2

Rajkowska K, Kunicka A (2005) The analysis of fermentation profiles and some genetic properties of mesophilic wine yeast strains. Food Sci Technol Qual 43:164-173

Redzepovic S, Orlic S, Majdak A, Kozina B, Volschenk H, ViljoenBloom M (2003) Differential malic acid degradation by selected strains of Saccharomyces during alcoholic fermentation. Int $\mathrm{J}$ Food Microbiol 83:49-61. doi:10.1016/S0168-1605(02)00320-3

Rosini G, Federici F, Vaughan AE, Martini A (1982) Systematics of the species of the yeast genus Saccharomyces associated with the fermentation industry. Appl Microbiol Biotechnol 15:188-193. doi:10.1007/BF00511247

Sabaté J, Cano J, Querol A, Guillamón JM (1998) Diversity of Saccharomyces strains in wine fermentations: analysis for two consecutive years. Lett Appl Microbiol 26:452-455. doi:10.1046/j.1472-765X.1998.00369.x

Salmon JM (1997) Enological fermentation kinetics of an isogenic ploidy series derived form an industrial Saccharomyces cerevisiae strain. J Ferment Bioeng 83:253-260. doi:10.1016/S0922338X(97)80988-9

Schwartz DC, Cantor C (1984) Separation of yeast chromosome-sized DNAs by pulsed field gradient gel electrophoresis. Cell 37:67-75. doi:10.1016/0092-8674(84)90301-5

Serra A, Strehaiano P, Taillandier P (2005) Influence of temperature and $\mathrm{pH}$ on Saccharomyces bayanus var. uvarum growth; impact of a wine yeast interspecific hybridization on these parameters. Int J Food Microbiol 104:257-265. doi:10.1016/j.ijfoodmicro. 2005.03 .006

Sipiczki M (2008) Interspecies hybridization and recombination in Saccharomyces wine yeasts. FEMS Yeast Res 8:996-1007. doi:10.1111/j.1567-1364.2008.00369.x

Sipiczki M (2011) Diversity, variability and fast adaptive evolution of the wine yeast (Saccharomyces cerevisiae) genome-a review. Ann Microbiol 61:85-93. doi:10.1007/s13213-010-0086-4

Sipiczki M, Romano P, Lipani G, Miklos I, Antunovics Z (2001) Analysis of yeasts derived from natural fermentation in a Tokaj winery. Antonie van Leeuwenhoek 79:97-105. doi:10.1023/ A:1010249408975

Spirek M, Yang J, Groth C, Petersen RF, Langkjaer RB, Naumova ES, Sulo P, Naumov GI, Piskur J (2003) High-rate evolution of Saccharomyces sensu lato chromosomes. FEMS Yeast Res 3:363-373. doi:10.1016/S1567-1356(02)00204-0

Tavares FC, Kido EA, Vencovsky R (1988) Recurrent selection in yeast. Yeast 4:477-486

Torija MJ, Beltran G, Novo M, Poblet M, Rozés N, Mas A, Guillamón JM (2003) Effect of organic acids and nitrogen source on alcoholic fermentation: study of their buffering capacity. J Agric Food Chem 51:916-922. doi:10.1021/jf020094r

Tosi E, Azzolini M, Guzzo F, Zapparoli G (2009) Evidence of different fermentation behaviours of two indigenous strains of Saccharomyces cerevisiae and Saccharomyces uvarum isolated from Amarone wine. J Appl Microbiol 107:210-218. doi:10.1111/ j.1365-2672.2009.04196.x

Turakainen H, Aho S, Korhola M (1993) MEL gene polymorphism in the genus Saccharomyces. Appl Environ Microbiol 59:2622-2630

Valadi H, Valadi A, Ansell R, Gustafsson L, Adler L, Norbeck J, Blomberg A (2004) NADH-reductive stress in Saccharomyces cerevisiae induces the expression of the minor isoform of glyceraldehyde-3-phosphate dehydrogenase (TDH1). Curr Genet 45:90-95. doi:10.1007/s00294-003-0469-1

Vaughan-Martini A, Martini A (1993) A taxonomic key for the genus Saccharomyces. Syst Appl Microbiol 16:113-119

Vezinhet F, Blodin B, Hallet JN (1990) Chromossomal DNA patterns and mitochondrial DNA polymorphisms as tool for identifcation of enological strains of Saccharomyces cerevisiae. Appl Microbiol Biotechnol 32:568-571

Volschenk H, Van Vuuren HJJ, Viljoen-Bloom M (2003) Maloethanolic fermentation in Saccharomyces and Schizosaccharomyces. Curr Genet 43:379-391. doi:10.1007/s00294-003-0411-6

Yarrow D (1998) Methods for the isolation, maintenance and identification of yeasts. In: Kurtzman CP, Fell JW (eds) The yeasts. A taxonomic study, Amsterdam, pp 77-100 